\title{
Empirical Analysis of Effect of Information Technology Capability on Performance of Private Universities in Kenya
}

\author{
Ruth Ndanu King'oo*, Linda Kimencu, PhD, Godfrey Kinyua, PhD \\ Department of Business Administration School of Business Kenyatta University, Kenya
}

\author{
*Corresponding Author: Ruth Ndanu King'oo, Department of Business Administration School of \\ Business Kenyatta University, Kenya
}

\begin{abstract}
Over the years, private universities in Kenya have reported poor performance due to various challenges including fierce competition, decline in quality of educational programs, quality of research, authenticity of degrees granted, flexibility of the university programs, innovations created, and the utilization of resources at their disposal. Despite the increasing number of students seeking higher education, these numbers have not translated to better performance in these Universities. Modern business environment calls for organizations, including private Universities to identify and exploit strategic capabilities for them to effectively compete and boost their performance. Information technology enables organizations to improve performance by improving competition, increasing the speed at which decisions are made and being responsive to changing customer needs. This study sought to determine the effect of information technology capability on performance of private universities in Kenya. The study was anchored on Resource-based view theory and was founded on positivist research philosophy. Cross-sectional descriptive survey research design was used to show the relationship existing between the study variables. The study targeted all 31 Kenyan private universities in Kenya as at 31st December 2016. 153 respondents from all the private universities in Kenya were sampled using proportionate stratified sampling. Primary data was collected from faculty deans, registrar's administrations and finance, human resources managers, and ICT managers. Data analysis was carried out using descriptive statistics; means, frequencies and standard deviations and inferential statistics (correlation and regression analysis). The findings of this study indicated that IT capability (mean= 3.44) was adopted in private universities in Kenya to a moderate extent. Correlation results showed positive correlations between university performance and the IT capability. The simple linear regression model was significant $(R$ square $=0.401 ; F(5,121)=16.184 ; P$-value $=0.001)$ and predicted $40.1 \%$ of all the variations in performance of private universities in Kenya. The coefficient of IT capability had a P-value of $(0.001<0.05)$ significance level. Thus, based on the P-value the study rejected the null hypothesis and concluded that IT capability significantly affect performance of private Universities in Kenya. Based on the findings and conclusions, the study therefore recommends that private universities in Kenya should map their IT capabilities that would enable them improve their infrastructure such as well-equipped computer laboratories to enable them span their businesses by automating their programmes and processes. Further, these universities should adopt a proactive stance by developing adaptable operating systems.
\end{abstract}

Keywords: IT Capability, Organization Performance, Private Universities

\section{INTRODUCTION}

Over the years, private universities in Kenya have reported poor performance due to various challenges including fierce competition, decline in quality of educational programs, quality of research, authenticity of degrees granted, flexibility of the university programs, innovations created, and the utilization of resources at their disposal. Efficiency of learning processes, which affects the acquired skills has also been questioned in these universities (Abong'o, 2007). Universities in Kenya and more specifically private universities have failed to produce graduates who meet industry demands. Although the number of higher education enrolment in these universities have increased, these numbers have not translated to better performance. Consequently, private universities have been reporting poor performance (Keller, 2014).

Owing to these challenges, establishing strategic capabilities such as IT capabilities becomes paramount for the universities to be competitive and at the same time achieve superior performance. Performance is the key force for the existence of all firms (Boon\& Yew, 2011). The Resource based view (RBV) theory points out that the ability of a firm to achieve a competitive advantage and to 
perform effectively will depend on the resources at the organization disposal. Keller (2014) observed that organizations require strategic capabilities such as Information technology for them to achieve superior performance. On the other hand, Chae et al. (2014) asserted that information technology can enable a firm to improve performance by improving competition, increasing the speed at which decisions are made and being responsive to changes.

IT capabilities involve the ability of an organization to use shareable resources which explains the way in which the organization can successfully manage its data and architectures, its communication capability and its portfolios (Lu\& Ramamurthy, 2011). It also relates to the ability of a firm's management to use the available IT resources to improve its enterprise activities and the ability of the organization to embrace new IT innovations to take advantage of new opportunities. Technology helps the firm to be adaptive to the changing customer needs. The connection between the activities of the enterprise and IT allows for quick, efficient and effective use of innovative strategies that leads to dynamics and re-engineering of the enterprise strategies and systems (Setia et al., 2013). In private universities Information technology can be measured using aspects such as infrastructure capability, IT business spanning capability, IT proactive stance, and University IT competence, and University information systems.

\section{Statement of the Problem}

The need for higher education in Kenya has provided a good market for private universities in Kenya for the last two decades(Rabah, 2015).Regardless of this rapid expansion of private universities, there are challenges that face these institutions arising from low funding by the owners or sponsors; increased intake of students without corresponding investment in human resources and facilities; low research capacity which cannot support development agenda; failure to attract research grants from industry and commerce as well as the government; and failure to produce graduates who meet industry demands (Abong'o, 2007). Their existence is equally threatened by heightened competition from more established public universities that have parallel programs. This is because public universities have the capacity to attract qualified instructors and research grants from the government and research institutions. As a result, these universities have continued to post poor results associated with quality of programs, flexibility of programs, resource utilization and research orientations (Muraguri, et al., 2017).

According to the Commission for University Education (CUE), some universities such as Kenya Methodist University (KEMU) the population of students has significantly reduced over time irrespective of massive facilities acquired (CUE, 2016). Similarly, other universities such Inorero University were forced to shut doors due to poor performance. Pioneer university rely heavily on a few programs to remain afloat. Performance in this sense is quality of programs, flexibility of programs, resource utilization, and research orientation (CUE, 2016). This clearly shows that there is need for identification and development of strategic capabilities if the private universities in Kenya will achieve performance that is sustainable. These challenges have painted a picture that private universities in Kenya are unable to provide the desired quality of education.

Several studies have been conducted attempting to show the relationship existing between the IT capability and performance. However, there are still gaps existing in literature. For instance, Sabherwal and Kirs (1994) sought to establish the alignment between organizational critical success factors and information technology capability in academic institutions. The study concluded that alignment positively influenced the performance and IT success in the firm. However, in this study IT capability was used as the predicted variable while in the current study it was used as a predictor variable.

Liu, Zhao, Wang and Xiao (2013) conducted a study on the impact of information technology capability on the performance of the organization. According to the results, IT capability favorably impacted in the performance of the organization. However, this study was a meta-analysis of information technology literature which lacks empirical support. Thus, a methodological gap was identified in the study.

Investigating the relationship between information technology capability and the performance of an organization, Chae, Koh and Prybutok (2014) showed that there lacked any favorable relationship 
between IT capability and the performance of an organization. However, the study was based on the IT industry and the findings may not be applicable in the education sector in Kenya.

While several studies have been conducted attempting to show the relationship existing between the study variable, there are still gaps existing in literature. This study establishes that there exist contextual, conceptual, and empirical gaps in literature which need to be filled. The study therefore seeks to establish the effect of IT capability (infrastructure capability, IT business spanning capability, IT proactive stance, University IT competence and University information systems) and performance of private universities in Kenya.

\section{LITERATURE REVIEW}

\subsection{Resource Based View Model}

The resource based view model developed by Penrose (1959) asserts that an organization can achieve superior performance by optimally utilizing the resources it owns and controls. Consequently, the manner in which the organization configures the resources affects its performance (Wernerfelt, 1984). The model further affirms that a firm can dominate its rivals based on the way they build, position and safeguard the resources that are distinct and allow them to gain an advantage over their rivals (Molloy, et al., 2011). According to Barney and Hesterly (2010), for resources to generate competitive advantage, they must be in a position to generate future benefit to the firm, a benefit that cannot be realized by rival firms, making them strategic. In strategic management literature, strategic resources are made up of the capabilities and competencies of the firm (Molloy, et al., 2011).

Competencies, on one hand are regarded as the organizations abilities that allow them to differentiate themselves and improve their service delivery by use of technological systems that are more responsive, which results to the organization gaining a competitive advantage in the marketplace (Arend\& Levesque, 2010). Capabilities on the other hand, are made up of a firm's knowledge, ability, skills, and experiences that makes it possible for the firm to operate and use its resources to perform effectively (Barney\&Hesterly, 2010). These capabilities enable the firm to operate above the ordinary thus enhancing its performance (Molloy, et al., 2011).

This model is essential in management as it concentrates on an organizations resources as the key source of enhanced performance and a competitive advantage in the market (McKelvie\& Davidsson, 2009). As such private universities through the adoption of the postulates of the model can improve their performance by differentiating their programmes from those of other universities making them inimitable and non-substitutable (Barney\&Hesterly, 2010). Additionally, private universities can use their IT capabilities to expand their business as well as reduce operational costs by automating their processes. Further, by adopting IT capabilities, universities are able to improve research, by providing online materials for their learners hence enabling them to write and publish journal articles and books.

\subsection{Empirical Literature Review}

Numerous studies have been conducted on study constructs which have showed mixed results. For instance, Sabherwal and Kirs(1994)showed that sophisticated IT management positively affected alignment and IT success while environmental uncertainty did positively affect IT success but not alignment. Integration was found to not affect IT success and alignment. Examining the relationship between the ability of information technology and organization capability, an empirical examination of business and information systems executives in 128 firms showed a significant positive relationship between IT capability and market capitalizing agility and operational adjustment agility (Lu\& Ramamurthy, 2011). Mithas, et al (2011) postulated that information management capability also positively affects the firm's management of customers, processes, and performance.

In a study on the impact of information technology capability on the performance of the organization, results showed that IT capability favorably impacted in the performance of the organization. Another finding was that the varied measures of performance and IT capability and the varied cultures had a significant impact on the relationship between the study variables but the different sources of data did not affect this relationship (Liu, et al., 2013).

Investigating the relationship between information technology capability and the performance of an organization, Chae, et al. (2014) found that there lacked any favorable relationship between IT 
capability and the performance of an organization. The results were different from other studies looked at earlier results which had showed a positive relationship. In addition, in the current study, the firms that were leading in IT capability performance was no better than the ones who did not have IT capability. The results of this study were based on data collected from 1991 to 2007.

In Kenya, evaluating the interaction between information technology capability, environmental conditions and competitiveness of consultancy firms in Nairobi County, Tanui(2015) found that IT capability positively influences firm competitiveness, IT capability also positively influences firm competence while at the same time firm competence partially mediates the relationship between IT capability and firm competitiveness. The moderating influence of the environmental conditions was found to be contingent upon the behaviour of the environmental conditions. In a study on the impact of information technology capability in the tourism state corporations in Kenya,Muthoka, et al. (2017)concluded that information technology capability has a significant effect on performance of tourism state corporations in Kenya. Further, Kyengo, Muathe and Kinyua (2019) concluded that information technology capability has a positive effect on performance of food processing firms in Nairobi City County, Kenya

Based on the reviewed empirical literature, the study found that there are gaps that exist in these studies. Many of the studies conducted previously have considered only one strategic resource or have considered strategic capabilities as a construct in totality. The current study however has disintegrated strategic capabilities to focus on the effect of IT capability specifically infrastructure capability, IT business spanning capability, IT proactive stance, University IT competence and University information systems and their relationship with university performance.

\subsection{Conceptual Framework}

The conceptual framework shown in figure 1 illustrate the relationship existing between the study variable as developed from reviewed literature.

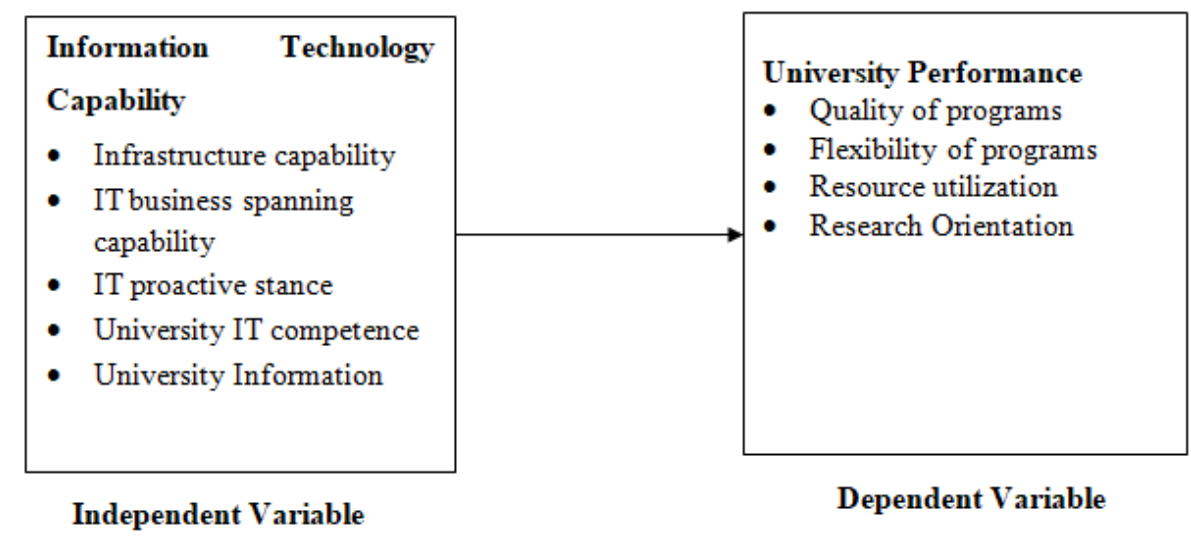

Figure1. Conceptual Framework

Source: Author (2019)

Arising from the reviewed literature, it is expected that information technology capability has a direct positive relationship with university performance. Consequently, it is hypothesized that;

H0: Information technology capability has no significant effect on performance of Private Universities in Kenya.

This hypothesis was tested against the alternative hypothesis that;

H1: Information technology capability has a significant effect on performance of Private Universities in Kenya.

\section{ReSEARCh Methodology}

The research used a positivist research philosophy which according to Creswell (2009) it makes it easier to determine probable relationship existing between the study constructs. Furthermore, the philosophy explains relationships by noting causes that affects results giving a basis for generalization and prediction. As noted by Kinyua (2015) positivism research philosophy is suitable for any 
statistical inquiry that seeks to offer a rational explanation concerning the relationship between research variables. The current research sought to use quantitative data to provide an explanation on the relationship between IT capabilities and performance of Private Universities in Kenya.

As Creswell (2009) notes, the major assumption of the positivist philosophy is that firms are rational and they seek rational explanations and solutions to their rational challenges. In addition, the study adopted a cross-sectional descriptive survey research design. According to Marshall and Rossman (2014), a descriptive survey is concerned with the process of data collection to help in the study hypothesis testing and answer the research questions. This research design has been successfully used in past empirical studies (Gatuyu \& Kinyua, 2020;King'oo, Linda \&Kinyua, 2020; Muthoni \& Kinyua, 2020; Ontita \& Kinyua, 2020).

The research targeted all 31 Kenyan private Universities as at $31^{\text {st }}$ December 2016. Proportionate stratified sampling method was used to choose the 153 respondents who was the sample from all the private universities in Kenya representing $60 \%$ of the target population. This study utilized primary data which was collected from the section heads in each of the departments of faculty deans, registrars and administrations and finance, human resources management, and IT managers. Descriptive statistics including means, frequencies and standard deviations were used for quantitative data analysis and presented inform of tables and graphs.

In addition, inferential statistics was also carried out using measures such as correlation and regression analysis to establish the extent and nature of the relationship between the variables of the study (Jobson, 2012). The study used the adjusted coefficient of determination (R-squared (R2)) to show the extent to which the changes in the university performance is explained by changes in IT capability in Private Universities in Kenya. Additionally, F-statistic was also tested at a confidence level of $95 \%$ to test the existence of a significant relationship between IT capability and performance of private universities in Kenya. P-values was used to help make a decision on test of hypothesis at 0.05 significant level and at 95\% confidence level (Sekaran, 2011).

\section{RESULTS AND DISCUSSIONS}

\subsection{Reliability of the Research Instruments}

Validity of the research instrument aimed at establishing how accurately the data obtained captured what they were designed and purported to measure. The study tested face validity, content validity and construct validity. Reliability of the research instrument was measured through Cronbach Alpha where a coefficient of greater than 0.7 was accepted as reliable. The results were as shown in Table 1

Table1. Reliability Coefficients

\begin{tabular}{|l|l|l|l|}
\hline Variable & Number of Items & Cronbach's Alpha Coefficient & Conclusion \\
\hline Information technology capability & 18 & 0.723 & Reliable \\
\hline Performance & 18 & 0.727 & Reliable \\
\hline Overall & & $\mathbf{0 . 7 2 5}$ & Reliable \\
\hline
\end{tabular}

Source: Research Data (2019)

From the Results shown in table 1, it was observed that both constructs had their Cronbach's Alpha Coefficient greater or equal to 0.7 with the aggregate coefficient being 0.725 . It was thus concluded that the study constructs were reliable.

\subsection{Descriptive Results for IT Capability}

In this section, descriptive statistics (minimum and maximum values, mean scores, standard deviation) for IT capability are presented. IT capability was measured through infrastructure capability, IT business spanning capability, IT proactive stance, university IT competence and university Information systems was the independent variable for the study. Table 2 shows the mean score for all the measurements of IT capability and their respective standard deviations.

Table2. Descriptive Statistics for IT Capability

\begin{tabular}{|l|l|l|l|l|l|}
\hline & n & Min & Max & Mean & Std. Deviation \\
\hline Infrastructure Capability & 127 & 2 & 4 & 3.65 & .450 \\
\hline IT business spanning capability & 127 & 1 & 4 & 3.62 & .711 \\
\hline IT proactive stance & 127 & 2 & 5 & 3.31 & .697 \\
\hline
\end{tabular}


Empirical Analysis of Effect of Information Technology Capability on Performance of Private Universities in Kenya

\begin{tabular}{|l|l|l|l|l|l|}
\hline University IT Competence & 127 & 3 & 5 & 3.69 & .478 \\
\hline University Information Systems & 127 & 3 & 5 & 3.94 & .561 \\
\hline Aggregate & $\mathbf{1 2 7}$ & & & $\mathbf{3 . 4 4}$ & $\mathbf{. 5 7 9}$ \\
\hline
\end{tabular}

Source: Research Data (2019)

It was observed in Table 2 that IT capability had an aggregate mean score of 3.44 indicating that IT capability was adopted in private universities in Kenya to a moderate extent. The respondents were in agreement in their responses as shown by a low standard deviation of 0.579 .

On the individual measures private universities in Kenya utilized the aspects university information systems, university IT competence, infrastructure Capability and IT business spanning capability to a great extent implying that these aspects greatly influenced private university performance (mean score $=3.94,3.69,3.65,3,62)$ respectively. On the other hand, IT proactive stance had the lowest means score of 3.31 implying that proactive stance in private universities in Kenya was moderately utilized. All the aspects of IT capability had low standard deviations indicating that there were minimum variations in the respondent's opinions concerning the extent to which these aspects influenced university performance.

\subsection{Descriptive Results for University Performance}

Descriptive statistics for university performance are presented in this section. Performance was operationalized through customer satisfaction, availability of teaching resources, entry requirements, non-academic programmes, curriculum revision, efficiency, number of journal articles published, and number of books published. Table 3 shows a summary of descriptive results on university performance.

Table3. Descriptive Statistics for University Performance

\begin{tabular}{|l|l|l|l|l|l|}
\hline & n & Min & Max & Mean & Std. Deviation \\
\hline Curriculum Revision & 127 & 1 & 5 & 3.95 & 1.083 \\
\hline Non-academic Programs & 127 & 1 & 5 & 3.86 & 1.031 \\
\hline Number of Books Published & 127 & 1 & 5 & 3.66 & 0.944 \\
\hline Customer Satisfaction & 127 & 2 & 4 & 3.65 & .450 \\
\hline Entry Requirements & 127 & 1 & 5 & 3.53 & 1.031 \\
\hline Journal Articles Published & 127 & 1 & 5 & 3.48 & 0.91 \\
\hline Availability of Teaching Resources & 127 & 1 & 5 & 3.41 & 1.01 \\
\hline Efficiency & 127 & 1 & 5 & 2.72 & 1.074 \\
\hline Aggregate & $\mathbf{1 2 7}$ & & & $\mathbf{3 . 5 7}$ & $\mathbf{1 . 0 3 5}$ \\
\hline
\end{tabular}

Source: Research Data (2019)

Results in table 3 show that the average mean score for performance was 3.57 which means that the respondents agreed that organizational performance had improved. At the same time the results showed that the respondents differed in their opinions on the extent to which performance of private universities in Kenya had improved as shown by a high standard deviation of 1.035. Specifically, respondents showed that curriculum revision had greatly improved in private universities as shown by a mean score of 3.95. However, there was a high disagreement on this attribute depicted by a standard deviation of 1.083 . Therefore, while some private universities had continuously reviewed their curriculum, others remained rigid.

It was also noted that non-academic programs, number of books published, customer satisfaction, and entry requirements had improved in private universities as shown by a mean score of 3.86, 3.66, 3.65, and 3.53 respectively. The number of journal articles published and availability of teaching resources remained constant as shown by a mean score of 3.48 and 3.41 respectively. Efficiency in private universities, though constant had the least mean score of 2.72 implying that majority of the respondents felt that there was no active pursuit by private universities to improve their efficiency. However, a high standard deviation of 1.074 suggests that while some private universities were reluctant to employ modern methods to improve efficiency, a good number endeavored to be efficient.

\section{INFERENTIAL ANALYSIS}

The study sought to establish the effect of IT capability on performance of private Universities in Kenya. To achieve this objective, the study carried out inferential analysis (correlation analysis and regression analysis). 


\subsection{Correlation Analysis}

Correlation analysis was conducted to establish the direction and the strength of the association of variables in the study (Jobson, 2012). The results of the correlation analysis were as shown in Table 4.

Table4. Correlations Analysis Results

\begin{tabular}{|l|l|l|l|}
\hline & & University Performance & $\begin{array}{l}\text { Information technology } \\
\text { capability }\end{array}$ \\
\hline $\begin{array}{l}\text { University } \\
\text { Performance }\end{array}$ & Pearson Correlation & 1 & \\
\hline & Sig. (2-tailed) & & \\
\hline & $\mathrm{N}$ & 127 & 1 \\
\hline $\begin{array}{l}\text { Information } \\
\text { technology capability }\end{array}$ & Pearson Correlation & $.291^{* *}$ & \\
\hline & Sig. (2-tailed) & .001 & 127 \\
\hline & $\mathrm{N}$ & 127 & \\
\hline
\end{tabular}

**. Correlation is significant at the 0.01 level (2-tailed).

*. Correlation is significant at the 0.05 level (2-tailed).

Source: Research Data (2019).

The results in Table 4 showed a significant weak positive correlation between university performance and information technology capability $(\mathrm{r}=0.291 ; \mathrm{n}=127 ; \mathrm{p}=0.001<0.05)$. These results show that there was a positive correlation between university performance and all the independent variables. These results concurred with Setia, et al. (2013) conclusions that IT significantly affects the performance of an organization by allowing for quick, efficient, and effective use of innovative strategies that lead to dynamics and re-engineering of the enterprise strategies and systems.

\subsection{Regression Analysis}

To establish the nature of the relationship existing between the variables university performance was regressed on IT capabilities. The objective of the study was to evaluate the effect of information technology capability on performance of private Universities in Kenya. To achieve this objective, the study tested the hypothesis that information technology capability has no significant effect on performance of private Universities in Kenya. The results were as shown in Tables 5, 6 and 7.

Table5. Model Summary

\begin{tabular}{|l|l|l|l|l|}
\hline Model & R & R Square & Adjusted R Square & Std. Error of the Estimate \\
\hline 1 & $.633^{\mathrm{a}}$ & .401 & .376 & .33020 \\
\hline
\end{tabular}

a. Predictors: (Constant), IT Capability

Source: Research Data (2019)

The results from Table 5 shows that the coefficient R Squared was found to be 0.401 indicating that the model predicted $40.1 \%$ changes in the performance of Private Universities in Kenya. The remaining 59.9\% the performance was predicted by other values not mentioned in the model. The analysis of variance results were as indicated in Table 6.

Table6. $A N O V A^{a}$

\begin{tabular}{|l|l|l|l|l|l|l|}
\hline \multicolumn{2}{|l|}{ Model } & Sum of Squares & df & Mean Square & F & Sig. \\
\hline \multirow{4}{*}{1} & Regression & 8.823 & 5 & 1.765 & 16.184 & $.000^{\mathrm{b}}$ \\
\cline { 2 - 7 } & Residual & 13.193 & 121 & .109 & & \\
\cline { 2 - 4 } & Total & 22.016 & 126 & & & \\
\hline
\end{tabular}

a. Dependent Variable: University Performance

b. Predictors: (Constant), IT Capability

Source: Research Data (2019)

The results in Table 6 shows that the F-statistic for the model was 16.184 which is greater than the Fcritical of 2.289 at $(5,121)$ implying that the model was fit in predicting university performance. The results also indicated that the model had a $P$ value of 0.00 which is less than 0.05 level of significance. This means that the model was significant in predicting university performance. The regression coefficient results were as indicated in table 7. 
Table7. Coefficients ${ }^{a}$

\begin{tabular}{|c|c|c|c|c|c|}
\hline \multirow{2}{*}{ Model } & \multicolumn{2}{|c|}{ Unstandardized Coefficients } & \multirow{2}{*}{$\begin{array}{l}\text { Standardized Coefficients } \\
\text { Beta }\end{array}$} & \multirow[b]{2}{*}{$\mathbf{t}$} & \multirow[b]{2}{*}{ Sig. } \\
\hline & B & Std. Error & & & \\
\hline (Constant) & 2.122 & .489 & & 4.340 & .000 \\
\hline IT Capability & .237 & .138 & .232 & 2.717 & .001 \\
\hline
\end{tabular}

1. Dependent Variable: University Performance

Source: Research Data (2019)

Table 7 shows the Beta coefficient for the constant was 2.122 alluding that if all other factors affecting the performance of private universities in Kenya were held constant, the performance of private universities in Kenya would be 2.122 . The results from the table also indicate that, a unit increase in IT Capability results in 0.237 increase in performance of private universities in Kenya provided all other factors are held constant.

From the results, IT capability had $\mathrm{P}$ value less than 0.05 indicating that the variable was significant in predicting performance of private universities in Kenya. Thus, based on the P-value the study rejected the null hypothesis and concluded that IT capability significantly affect performance of private Universities in Kenya. The results were consistent with the conclusions of Chae, et al. (2014), asserting that information technology enables the firm to improve performance by increasing the speed at which decisions are made and being responsive to changes. Further, the results were in line with Vesalainen and Hakala (2014) conclusions that technology helps a firm to be adaptive to the changing customer needs thereby improving competition. The results also concurred with $\mathrm{Lu}$ and Ramamurthy(2011) postulation that IT capability offer a firm the ability to use of shareable resources enabling the university to successfully manage its data and communication capability.

\section{CONCLUSION}

This study sought to determine the effect of IT capability and performance of private universities in Kenya. The study found that IT capability had a significant positive effect on performance and was perceived as a key driving factor in performance of private Universities in Kenya in that it aids in decision making through swift response and adoption of the changing customer needs.

\section{RECOMMENDATION}

Based on the conclusions, the study recommends that private universities in Kenya should map their IT capabilities that would enable them improve their infrastructure such as well-equipped computer laboratories to enable them span their businesses by automating their programmes and processes. Further, universities should adopt a proactive stance by developing adaptable operating systems.

\section{REFERENCES}

[1] Abong'o, E. B. (2007). Responses adopted by private Universities in Kenya to cope with the changing higher Education Environment. (Unpublished MBA Project), University of Nairobi, Kenya.

[2] Arend, R.J. \& Levesque, M. (2010). Is the resource-based view a practical organizational theory? Organization Science, Vol. 21 No. 4, pp. 913-30.

[3] Barney, J. B. \& Hesterly, W.S (2010). Strategic management and competitive advantage concept. Upper saddle River, N.J: Pearson Prentice Hall.

[4] Bidmeshgipour, M. (2012). The relationship of strategic human resource management practices and business performance considering the mediating roleof resource based view of the firm (Doctoral dissertation), University of Teknologi.

[5] Boon-Itt, S., \& Yew W. C. (2011). The moderating effects of technological and demand uncertainties on the relationship between supply chain integration and customer delivery performance. International Journal of Physical Distribution \& Logistics Management, 41(3), 253-276.

[6] Chae, H. C., Koh, C. E., \& Prybutok, V. R. (2014). Information technology capability and firm performance: Contradictory findings and their possible causes. Mis Quarterly, 38(1), 305-326.

[7] Commission for University Education. (2016). Annual report. Nairobi: Commission for University Education. 
[8] Creswell, J. W., \& Zhang, W. (2009). The application of mixed methods designs to trauma research. Journal of Traumatic Stress: Official Publication of The International Society for Traumatic Stress Studies, 22(6), 612-621.

[9] Deya, J., Oloko, M., \& Orwa, G. (2017). The relationship between dynamic ICT capabilities and competitive advantage of technical, vocational and entrepreneurship training institutions in Western Kenya Region.

[10] Gatuyu, C. M. \& Kinyua, G. M. (2020). Role of Knowledge Acquisition on Firm Performance in the Context of Small and Medium Enterprises in Meru County, Kenya. Journal of World Economic Research, 9(1): 27-32.

[11] Jobson, J. (2012). Applied multivariate data analysis: volume II: Categorical and Multivariate Methods. Springer Science \& Business Media.

[12] Keller, R. H. (2014). Is team based tacit knowledge transferable? Players as strategic resources. Journal of Management Policy and Practice, 15(4), 40.

[13] Kilika, J. M., K'Obonyo, P. O., Ogutu, M., \& Munyoki, J. M. (2012). The Mediating Role of University Industry Collaboration on the Relationship between Human Resource Development, Infrastructure and Performance of Universities in Kenya.Asia Pacific Journal of Advanced Business and Social Studies, Vol.2 (1), 9(3), 23.

[14] King'oo, R. N., Kimencu, L. \&Kinyua, G. (2020). The Role of Networking Capability on Organization Performance: A Perspective of Private Universities in Kenya. Journal of Business and Economic Development, 5(3): 178-186.

[15] Kinyua, G. M. (2015). Relationship between Knowledge Management and Performance of Commercial Banks in Kenya. Doctoral Dissertation; Kenyatta University, Nairobi, Kenya.

[16] Kyengo, J. M., Muathe, S. M. A., \& Kinyua, G. M. (2019). Empirical Analysis of the Effect of Information Technology Capability on Performance of Food Processing Firms in Nairobi City County, Kenya. Archives of Business Research, 7(7), 31-45.

[17] Liu, P., Zhao, R. Y., Wang, W. L., \& Xiao, J. (2013). Information technology capability and firm performance: A meta-analysis. In Service Systems and Service Management (ICSSSM), 2013 10th International Conference on (pp. 719-724).

[18] Lu, Y., \& Ramamurthy, K. (2011). Understanding the link between information technology capability and organizational agility: An empirical examination. Mis Quarterly, 931-954.

[19] Marshall, C., \& Rossman, G. B. (2014). Designing qualitative research. Sage publications.

[20] McKelvie, A. \& Davidsson, P. (2009). From resource base to dynamic capability: an investigation of new firms. British Journal of Management 20(S1), S63-S80.

[21] Mithas, S., Ramasubbu, N., \& Sambamurthy, V. (2011). How information management capability influences firm performance. MIS quarterly, 237-256.

[22] Molloy, J. C., Chadwick, C., Ployhart, R. E., \& Golden, S. J. (2011). Making intangibles "tangible" in tests of resource-based theory: A multidisciplinary construct validation approach. Journal of Management, 37(5), 1496-1518.

[23] Muraguri, C., Kimencu, L., \& Thuo, K. (2017). The Influence of Organizational Leadership on Performance of Universities in Kenya. African Multidisciplinary Journal of Research, 2(1).

[24] Muthoka, M., Oloko, M., \& Obonyo, L. (2017). Effect of information technology on performance of the tourism state owned corporations in Kenya. European Journal of Business and Strategic Management, 2(3), 29-57.

[25] Muthoni, D. M. \& Kinyua, G. M. (2020). Corporate Reputation and Firm Performance: An Empirical Analysis of Motor Vehicle Assemblers in Nairobi City County, Kenya. Journal of Business and Economic Development, 5(2): 73-81.

[26] Ochieng, O. E. (2015). The influence of intellectual capital on the performance of small and medium enterprises a case of Mombasa County Kenya (Doctoral dissertation), school of business, university of Nairobi.

[27] Oketch, M. O. (2003). The growth of private university education in Kenya: The promise and challenge. Peabody Journal of Education, 78(2), 18-40.

[28] Ontita, J. \& Kinyua, G. M. (2020). Role of Stakeholder Management on Firm Performance: An Empirical Analysis of Commercial Banks in Nairobi City County, Kenya. Journal of Business and Economic Development, 5(1): 26-35.

[29] Penrose, E.T. (1959). The Growth of the Firm. Wiley: NewYork.

[30] Rabah, K. (2015). Effects of competitive advantage on organizational effectiveness in higher education institutions: a case of Kabarak University. American Sociological Review, 48(3), 147-160. 
[31] Sabherwal, R., \& Kirs, P. (1994). The alignment between organizational critical success factors and information technology capability in academic institutions. Decision Sciences, 25(2), 301-330.

[32] Sekaran, U. (2011). Research methods: A skill building approach. John Wiley \& Sons.

[33] Setia, P., Venkatesh, V., \& Joglekar, S. (2013). Leveraging digital technologies: How information quality leads to localized capability and customer service performance. Mis Quarterly, 37(2).

[34] Tanui, J. K. (2015). Interaction between information technology capability, environmental conditions and competitiveness of consultancy firms in Nairobi County, Kenya (Doctoral dissertation), school of business, Kenyatta University.

[35] Vesalainen, J., \& Hakala, H. (2014). Strategic capability architecture: The role of network capability. Industrial Marketing Management, 43(6), 938-950.

[36] Wernerfelt, B. (1984). A Resource-based View of the Firm. “ Strategic Management Journal, Vol. 5(2), pp. 171-180.

[37] Yesil, S., \& Kaya, A. (2013). The effect of organizational culture on firm financial performance: Evidence from a developing country. Procedia-Social and Behavioural Sciences, 81, 428-437.

\section{AUTHORS' BIOGRAPHY}

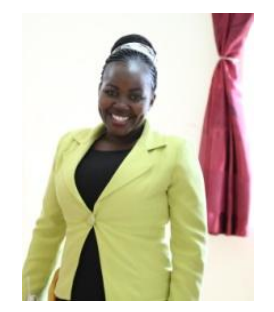

Ruth Ndanu King'oo, is a $\mathrm{PhD}$ graduand of Kenyatta University, Department of Business Administration, School of Business.

Dr. Linda Kimencu, $\mathrm{PhD}$ is a Lecturer at Kenyatta University, Department of Business Administration, School of Business

Dr. Godfrey Kinyua, $\mathrm{PhD}$ is a Lecturer at Kenyatta University, Department of Business Administration, School of Business

Citation: Ruth Ndanu King'oo, Linda Kimencu, PhD, Godfrey Kinyua, PhD. "Empirical Analysis of Effect of Information Technology Capability on Performance of Private Universities in Kenya" International Journal of Managerial Studies and Research (IJMSR), vol 8, no. 11, 2020, pp. 52-61. doi: https://doi.org/10.20431/23490349.0811006.

Copyright: (c) 2020 Authors. This is an open-access article distributed under the terms of the Creative Commons Attribution License, which permits unrestricted use, distribution, and reproduction in any medium, provided the original author and source are credited. 